\title{
Imaging biomarkers for predicting poor prognosis of hepatocellular carcinoma: a review
}

\author{
Yun Zhang', Zi-Xing Huang', Jie Chen'1, Yu-Jun Shi², Han-Yu Jiang', Li-Kun Cao³, Bin Song' \\ 'Department of Radiology, West China Hospital, Sichuan University, Chengdu 610041, Sichuan, China. \\ 2Laboratory of Pathology, Key Laboratory of Transplant Engineering and Immunology, NHC, West China Hospital, Sichuan \\ University, Chengdu 610041, Sichuan, China. \\ ${ }^{3}$ Department of Radiology, Peking Union Medical College Hospital (Dongdan campus), Beijing 100730, China.
}

Correspondence to: Prof. Bin Song, Department of Radiology, Sichuan University West China Hospital, No. 37, Guoxue Alley, Chengdu 610041, Sichuan, China. E-mail: anicesong@vip.sina.com

\begin{abstract}
How to cite this article: Zhang Y, Huang ZX, Chen J, Shi YJ, Jiang HY, Cao LK, Song B. Imaging biomarkers for predicting poor prognosis of hepatocellular carcinoma: a review. Hepatoma Res 2020;6:30. http://dx.doi.org/10.20517/2394-5079.2020.17
\end{abstract}

Received: 26 Feb 2020 First Decision: 2 Apr 2020 Revised: 21 Apr 2020 Accepted: 24 Apr 2020 Published: 16 Jun 2020

Science Editor: Guido Guenther Gerken Copy Editor: Jing-Wen Zhang Production Editor: Tian Zhang

\begin{abstract}
Hepatocellular carcinoma (HCC) is a primary malignancy of the liver with a high mortality rate. Heterogeneity is the main biological characteristic of HCC, which manifests through the different biological behaviors of each phenotype and ultimately, affects patient prognosis and treatment efficacy. Various aggressive biological behaviors are considered to be associated with the poor prognosis of HCC patients including poor differentiation, microvascular invasion, intracellular fat accumulation, invasive growth, bile duct invasion or tumor thrombosis, and tumor spread and metastasis, and have been reported as prognostic biomarkers. In addition, HCC results from multifactor synergistic damage, and various factors related to genetics, molecular pathology and immunohistochemistry such as $\beta$-catenin, Ki67, cytokeratin-19, and epithelial cell adhesion molecule have an impact on HCC differentiation and prognosis. This article is an overview of the biological behaviors that lead to poor prognosis of $\mathrm{HCC}$, and the roles of morphological and quantitative noninvasive imaging biomarkers in the evaluation and prediction of these behaviors. Some common biomarkers related to genetics, molecular pathology and immunohistochemistry are also briefly summarized. It is hoped that this review will provide clinicians and radiologists with an update on the development of liver imaging, and provide directions for the combination of radiology, genetics, molecular pathology and histopathology to better predict the prognosis of HCC patients.
\end{abstract}

Keywords: Hepatocellular carcinoma, poor prognosis, biological behaviors, imaging biomarkers, genetics, molecular pathology, immunohistochemistry 


\section{INTRODUCTION}

Liver cancer is the sixth most prevalent cancer and the fourth leading cause of cancer-related death worldwide. Hepatocellular carcinoma (HCC), mostly due to liver cirrhosis, accounts for $75 \%-80 \%$ of all liver cancers $^{[1]}$. Heterogeneity is the main biological characteristic of HCC, which manifests through different biological behaviors of each phenotype and ultimately, affects patient prognosis and treatment efficacy. Various aggressive biological behaviors including poor differentiation, microvascular invasion (MVI), intracellular fat accumulation, invasive growth, bile duct invasion or tumor thrombosis, and tumor spread and metastasis, have been reported to have an impact on clinical outcomes and the prognosis of HCC patients $^{[2-6]}$.

Liver imaging, a noninvasive method for visualizing tumor morphology and function, can provide a clear diagnosis and assessment of HCC in the presence of risk factors, and has flourished in recent decades with the potential to better depict the complex biological behaviors of HCC with relevant morphological and quantitative biomarkers ${ }^{[7-13]}$. Traditional imaging, including contrast-enhanced ultrasound, multi-phase dynamic enhanced computed tomography (CT) or magnetic resonance imaging (MRI), and fluoro-deoxyglucose/positron emission tomography (FDG/PET), play significant roles in the characterization of HCC as most have a typical blood supply and morphological characteristics. Functional imaging, including diffusionweighted imaging (DWI), chemical-shift MRI, magnetic resonance elastography (MRE), and MRI with liverspecific contrast, can provide cellular and metabolic information for the grading and staging of $\mathrm{HCC}^{[14]}$. Furthermore, improvements in advanced imaging analysis, including radiomics and artificial intelligence (AI), have introduced enormous potential for assessing the aggressiveness of HCC and prognostication of patients. Table 1 shows the aggressive biological behaviors associated with poor prognosis of HCC patients and their pathological basis, as well as morphological and qualitative imaging biomarkers that can be used to evaluate and predict biological behaviors. In addition, HCC is the result of multifactor synergistic damage, and various factors related to genetics, molecular pathology and immunohistochemistry also have an impact on HCC differentiation and prognosis ${ }^{[15]}$.

This article reviews the imaging biomarkers for aggressive behaviors associated with a poor prognosis in HCC patients, and the roles of different imaging methods and related biomarkers in the evaluation and prediction of these behaviors [Table 2]. A better understanding of these imaging features and their correlation with pathology can help clinicians to design the most appropriate treatment plans for HCC. In addition, a combination or confrontation of imaging signs with other biomarkers may be a direction for future research to better predict the prognosis of HCC.

\section{POOR DIFFERENTIATION}

Differentiation refers to the dedifferentiation of premalignant nodules until the development of HCC itself. The degree of differentiation of HCC is the key to prognosis of HCC patients ${ }^{[16]}$. Several pathological alterations are involved in loss of differentiation in HCC such as neoangiogenesis, disordered cellular structure, impairment of Kupffer cells and hepatocytes, and increased glucose metabolism in tumor cells.

\section{NEOANGIOGENESIS}

Neovascularization provides the basis for oxygen and nutrition for tumor growth, progression and metastasis. The unpaired arteries are new vessels which form through neovascularization, and play a crucial role both in the occurrence and development of $\mathrm{HCC}^{[17]}$.

As most HCCs show a typical enhancement pattern such as hyperenhancement in the hepatic arterial phase, and washout appearance in the portal venous and/or delayed phases relative to the surrounding tissue, traditional imaging technologies such as contrast-enhanced ultrasound (CEUS), dynamic contrast-enhanced 
Table 1. The aggressive biological behaviors associated with poor prognosis in HCC and related imaging biomarkers

\begin{tabular}{|c|c|c|c|}
\hline $\begin{array}{l}\text { Aggressive } \\
\text { biological behaviors }\end{array}$ & Pathological basis & Morphological imaging biomarkers & Quantitative imaging biomarkers \\
\hline \multicolumn{4}{|l|}{ Poor differentiation } \\
\hline Neoangiogenesis & $\begin{array}{l}\text { Formation of unpaired } \\
\text { arteries }\end{array}$ & $\begin{array}{l}\text { Hyperenhancement in the hepatic arterial } \\
\text { phase and washout appearance in the portal } \\
\text { venous and/or delayed phases relative to the } \\
\text { surrounding tissue. (Contrast enhanced-US, } \\
\text { dynamic contrast enhanced-CT or MRI) }\end{array}$ & $\begin{array}{l}\text { Enhancement values of tumor tissue (Dynamic } \\
\text { contrast enhanced-CT); Wash-out rate: the } \\
\text { interval time of wash-out after injection of } \\
\text { contrast agent. (Time-intensity curve analysis } \\
\text { of Contrast enhanced-US); Microvascular } \\
\text { density: } \mathrm{K}^{\text {trans }}, \mathrm{K}_{\mathrm{ep}}, \mathrm{V}_{\mathrm{e}} \text {, iAUC (Free-breathing } \\
\text { DEC-MRI using gadoxetic acid) }\end{array}$ \\
\hline $\begin{array}{l}\text { Restricted diffusion } \\
\text { movement of water } \\
\text { molecules within } \\
\text { tumor cells }\end{array}$ & $\begin{array}{l}\text { Disordered cellular } \\
\text { structure }\end{array}$ & High-intensity on DWI images & $\begin{array}{l}\text { Value of ADC (DWI, inconsistent); Value of D } \\
\text { and ADC (DWI, IVIM); Values of MK and ADC } \\
\text { (DKI); Tumor stiffness (MRE) }\end{array}$ \\
\hline $\begin{array}{l}\text { Decreased uptake of } \\
\text { liver-specific contrast } \\
\text { agents }\end{array}$ & $\begin{array}{l}\text { Impairment of Kupffer } \\
\text { cells; decrease in } \\
\text { OATPs transporters }\end{array}$ & $\begin{array}{l}\text { High-intensity on contrast enhanced-MRI with } \\
\text { SPION; low-intensity on the HBP of contrast } \\
\text { enhanced-MRI with Gd-EOB-DTPA }\end{array}$ & $\begin{array}{l}\text { High-intensity on contrast enhanced-MRI with } \\
\text { SPION; low-intensity on the HBP of contrast } \\
\text { enhanced-MRI with Gd-EOB-DTPA }\end{array}$ \\
\hline FDG concentration & $\begin{array}{l}\text { Glucose metabolism } \\
\text { increased in tumor } \\
\text { cells }\end{array}$ & $\begin{array}{l}\text { Uptake of fluorine-18 fluorodeoxyglucose on PET } \\
\text { imaging }\end{array}$ & Increase of SUV \\
\hline Microvascular invasion & $\begin{array}{l}\text { Tumor thrombi } \\
\text { invading microvessels }\end{array}$ & $\begin{array}{l}\text { Larger diameter and tumor size, multiple } \\
\text { lesions, incomplete capsule, non-smooth } \\
\text { tumor margins, irregular rim-like arterial phase } \\
\text { hyperenhancement, tumor multifocality, and } \\
\text { "mosaic" architecture; hypo-intensity on the HBP } \\
\text { of contrast enhanced-MRI Gd-EOB-DTPA }\end{array}$ & $\begin{array}{l}\text { Higher MK value of DKI; radiomics signatures } \\
\text { related to tumor size and intra-tumoral } \\
\text { heterogeneity; texture analysis }\end{array}$ \\
\hline $\begin{array}{l}\text { Intracellular fat } \\
\text { accumulation }\end{array}$ & $\begin{array}{l}\text { Steatosis occurs in the } \\
\text { context of ischemia } \\
\text { and hypoxia as a result } \\
\text { of decreased portal } \\
\text { vein and nontumoral } \\
\text { artery flow and } \\
\text { insufficient unpaired } \\
\text { arteries }\end{array}$ & $\begin{array}{l}\text { Intra-tumoral fat infiltration on in/out of phase } \\
\text { (Chemical-shift MRI) }\end{array}$ & $\begin{array}{l}\text { Intra-tumoral fat infiltration on in/out of phase } \\
\text { (Chemical-shift MRI) }\end{array}$ \\
\hline $\begin{array}{l}\text { Invasive growth } \\
\text { pattern }\end{array}$ & $\begin{array}{l}\text { Invasion of cancer cells } \\
\text { into adjacent tissues } \\
\text { and the vascular } \\
\text { lymphatic system }\end{array}$ & $\begin{array}{l}\text { Infiltrative appearance; portal vein tumor } \\
\text { thrombosis; mass with ill-defined with } \\
\text { heterogeneous attenuation/signal intensity; }\end{array}$ & / \\
\hline $\begin{array}{l}\text { Bile duct invasion or } \\
\text { tumor thrombosis }\end{array}$ & $\begin{array}{l}\text { Bile duct invasion or } \\
\text { tumor thrombosis }\end{array}$ & $\begin{array}{l}\text { Frequently associated with obstructive jaundice, } \\
\text { cholangitis, biliary bleeding; a soft tissue } \\
\text { mass with proximal bile duct dilatation and a } \\
\text { similar enhancement pattern to HCC; filling } \\
\text { defect in the bile duct, unexpected obstruction } \\
\text { of the bile duct, and cholangiectasis in MR } \\
\text { cholangiopancreatography }\end{array}$ & / \\
\hline $\begin{array}{l}\text { Tumor spread and } \\
\text { metastasis }\end{array}$ & $\begin{array}{l}\text { Cell proliferation and } \\
\text { colony formation, EMT } \\
\text { program start-up }\end{array}$ & $\begin{array}{l}\text { Intrahepatic micrometastasis; extrahepatic } \\
\text { metastasis; [Imaging features of metastasis, } \\
\text { (Contrast enhanced-US, dynamic contrast } \\
\text { enhanced-CT or MRI, PET imaging)] }\end{array}$ & / \\
\hline
\end{tabular}

HCC: hepatocellular carcinoma; US: ultrasonography; CT: computed tomography; MRI: magnetic resonance imaging; DWI: diffusionweighted imaging; IVIM: intravoxel incoherent motion; D: diffusion coefficient: ADC: apparent diffusion coefficient; MK: mean apparent kurtosis coefficient; DKI: diffusion kurtosis imaging; MRE: magnetic resonance elastography; OATPs: organic anionic transporting polypeptides; SPION: superparamagnetic iron-oxide nanoparticles; HBP: hepatobiliary phase; Gd-EOB-DTPA: gadolinium-ethoxy benzyl-diethylenetriamine penta-acetic acid; FDG: fludeoxyglucose; 18F-FDG: fluorine-18 fluorodeoxyglucose; PET: positron emission tomography; SUV: standardized uptake value; MRCP: magnetic resonance cholangiopancreatography; EMT: epithelial-mesenchymal transition; /: none

CT or MRI are used for the diagnosis of $\mathrm{HCC}^{[18,19]}$. Although the typical enhancement patterns are helpful in the diagnosis of HCC, they do not provide information for the degree of differentiation in HCC. Recently, time-intensity curve analysis, a quantitative CEUS analysis method, has been used to predict the degree of HCC differentiation ${ }^{[20,21]}$. Wash-out rate, one of the time-intensity curve-related parameters, is defined as the interval time of wash-out manifestation after injection of a contrast agent, which is recommended to identify tumor differentiation of HCC. As reported by Feng et al. ${ }^{[20]}$, the cut-off value of $120 \mathrm{~s}$ after contrast agent injection shows high accuracy for distinguishing well-differentiated HCC from poorly and 
Table 2. Different imaging methods and biomarkers for predicting poor prognosis of HCC

\begin{tabular}{|c|c|c|c|}
\hline $\begin{array}{l}\text { Biological } \\
\text { behaviors }\end{array}$ & $\begin{array}{l}\text { Imaging } \\
\text { methods }\end{array}$ & Related imaging biomarker & Roles and characteristics \\
\hline \multirow[t]{3}{*}{ Neoangiogenesis } & CEUS & $\begin{array}{l}\text { Typical enhancement features; wash-out rate (time- } \\
\text { intensity curve analysis) }\end{array}$ & $\begin{array}{l}\text { Surveillance and rapid diagnostic, reveal morphologic } \\
\text { changes, convenient and radiation-free }\end{array}$ \\
\hline & DCE-CT & $\begin{array}{l}\text { Typical enhancement features; enhancement values } \\
\text { of tumor tissue }\end{array}$ & $\begin{array}{l}\text { Diagnosis and differential diagnosis, CT values } \\
\text { indicate the degree of enhancement }\end{array}$ \\
\hline & DCE-MRI & $\begin{array}{l}\text { Typical enhancement features; microvascular } \\
\text { density }\left(\mathrm{K}^{\text {trans }}, \mathrm{K}_{\mathrm{ep}}, \mathrm{V}_{\mathrm{e}}, \mathrm{i} \mathrm{AUC}\right)\end{array}$ & $\begin{array}{l}\text { Diagnosis and differential diagnosis, provide } \\
\text { quantitative information of blood perfusion of tumor }\end{array}$ \\
\hline \multirow{4}{*}{$\begin{array}{l}\text { Restricted } \\
\text { diffusion } \\
\text { (disordered } \\
\text { cellular structure) }\end{array}$} & DWI & Value of ADC & \multirow{3}{*}{$\begin{array}{l}\text { Provide information regarding physiological tissue } \\
\text { characteristics and heterogeneity }\end{array}$} \\
\hline & IVIM & Value of $D$ and $A D C$ & \\
\hline & DKI & Values of MK and ADC & \\
\hline & MRE & Tumor stiffness & $\begin{array}{l}\text { Measuring the viscoelastic properties of the liver and } \\
\text { assessing tumor stiffness, might be associated with } \\
\text { the grade of the tumor }\end{array}$ \\
\hline \multirow[t]{2}{*}{$\begin{array}{l}\text { Decreased uptake } \\
\text { of liver-specific } \\
\text { contrast agents }\end{array}$} & $\begin{array}{l}\text { SPION enhanced- } \\
\text { MRI }\end{array}$ & High-intensity (impairment of Kupffer cells) & $\begin{array}{l}\text { Diagnosis and differential diagnosis; low sensitivity of } \\
\text { characterization of HCC; can be used as a means of } \\
\text { evaluating treatment response of HCC }\end{array}$ \\
\hline & $\begin{array}{l}\text { Gd-EOB-DTPA } \\
\text { enhanced-MRI }\end{array}$ & $\begin{array}{l}\text { Low-intensity on the HBP images (decrease of } \\
\text { OATPs transporters) }\end{array}$ & $\begin{array}{l}\text { Early diagnosis, precise characterization, follow-up } \\
\text { and monitoring of HCC; High sensitivity }\end{array}$ \\
\hline $\begin{array}{l}\text { FDG } \\
\text { concentration }\end{array}$ & PET imaging & Standardized uptake value & $\begin{array}{l}\text { A sensitive indicator of tumor viability; limited to the } \\
\text { level of diagnosis of HCC }\end{array}$ \\
\hline \multirow[t]{4}{*}{$\begin{array}{l}\text { Microvascular } \\
\text { invasion }\end{array}$} & $\begin{array}{l}\text { CEUS; DCE-CT/ } \\
\text { MRI }\end{array}$ & $\begin{array}{l}\text { Larger diameter and tumor size, multiple lesions, } \\
\text { incomplete capsule, non-smooth tumor margins, } \\
\text { irregular rim-like arterial phase hyperenhancement, } \\
\text { tumor multifocality, and 'mosaic' architecture }\end{array}$ & $\begin{array}{l}\text { Diagnosis and assessment. Detection and } \\
\text { assessment of multiple morphology imaging features }\end{array}$ \\
\hline & DKI & Higher MK value & $\begin{array}{l}\text { Provide quantitative information of the presence of } \\
\mathrm{MVI}\end{array}$ \\
\hline & $\begin{array}{l}\text { Gd-EOB-DTPA } \\
\text { enhanced-MRI }\end{array}$ & Hypo-intensity on the HBP images & $\begin{array}{l}\text { Assistant diagnosis; auxiliary feature (in conjunction } \\
\text { with other clinical indicators) }\end{array}$ \\
\hline & $\mathrm{Al}$ & $\begin{array}{l}\text { Radiomics signatures related to tumor size and } \\
\text { intra-tumoral heterogeneity; texture features }\end{array}$ & $\begin{array}{l}\text { Intelligent and noninvasive means for the prediction } \\
\text { of tumor heterogeneity }\end{array}$ \\
\hline $\begin{array}{l}\text { Intracellular fat } \\
\text { accumulation }\end{array}$ & $\begin{array}{l}\text { Chemical-shift } \\
\text { MRI }\end{array}$ & Intra-tumoral fat infiltration on in/out of phase & $\begin{array}{l}\text { Monitor the presence of intra-tumoral fat infiltration } \\
\text { in tumor; related to the histological degree of HCC; } \\
\text { optimize disease management }\end{array}$ \\
\hline $\begin{array}{l}\text { Invasive growth } \\
\text { pattern }\end{array}$ & $\begin{array}{l}\text { CEUS; DCE-CT/ } \\
\text { MRI }\end{array}$ & $\begin{array}{l}\text { Infiltrative appearance; PVTT; mass with ill-defined } \\
\text { and heterogeneous attenuation/signal intensity }\end{array}$ & $\begin{array}{l}\text { Diagnosis and differential diagnosis; detection and } \\
\text { assessment of multiple morphology imaging features }\end{array}$ \\
\hline \multirow{2}{*}{$\begin{array}{l}\text { Bile duct invasion } \\
\text { or tumor } \\
\text { thrombosis }\end{array}$} & $\begin{array}{l}\text { CEUS; DCE-CT/ } \\
\text { MRI }\end{array}$ & $\begin{array}{l}\text { A soft tissue mass with proximal bile duct dilatation } \\
\text { and a similar enhancement pattern to } \mathrm{HCC}\end{array}$ & Rapid diagnosis and differential diagnosis \\
\hline & MRCP & $\begin{array}{l}\text { Filling defect in the bile duct, unexpected obstruction } \\
\text { of the bile duct }\end{array}$ & $\begin{array}{l}\text { Noninvasive diagnosis and characterization without } \\
\text { contrast agents }\end{array}$ \\
\hline \multirow[t]{3}{*}{$\begin{array}{l}\text { Tumor spread and } \\
\text { metastasis }\end{array}$} & CEUS & Imaging features of metastasis & $\begin{array}{l}\text { Limited to intrahepatic metastasis, convenient and } \\
\text { radiation-free }\end{array}$ \\
\hline & DCE-CT/MRI & Imaging features of metastasis & Intrahepatic and extrahepatic metastasis \\
\hline & PET imaging & Standardized uptake value & $\begin{array}{l}\text { Show advantages in detecting distant metastasis and } \\
\text { lymph node metastasis }\end{array}$ \\
\hline
\end{tabular}

HCC: hepatocellular carcinoma; CEUS: contrast enhanced ultrasonography; DCE-CT: dynamic contrast enhanced computed tomography; DEC-MRI: dynamic contrast enhanced magnetic resonance imaging; DWI: diffusion-weighted imaging; IVIM: intravoxel incoherent motion; D: diffusion coefficient: ADC: apparent diffusion coefficient; MK: mean apparent kurtosis coefficient; DKI: diffusion kurtosis imaging; MRE: magnetic resonance elastography; SPION: superparamagnetic iron-oxide nanoparticles; Gd-EOB-DTPA: gadolinium-ethoxy benzyl-diethylenetriamine penta-acetic acid; HBP: hepatobiliary phase; Al: artificial intelligence; PVTT: portal vein tumor thrombosis; MRCP: MR cholangiopancreatography; PET: positron emission tomography

moderately differentiated HCC. Time-intensity curve analysis is advantageous in showing the perfusionrelated characteristics of different grades of HCCs, and providing quantitative indices for the assessment of hemodynamics in tumors, which is convenient and radiation-free.

Microvascular density, as assessed by immunohistochemistry, is generally considered as an indicator of angiogenesis in malignant tumors, and is an effective prognostic marker in patients with HCC $^{[22]}$. The DCE-MRI derived $K^{\text {trans }}, K_{e p}$ and $V_{e}$, and the semi-quantitative parameter such as the initial area under the gadolinium concentration-time curve of the free-breathing DCE-MRI using gadoxetic acid, are highly associated with histological grades and microvascular density of HCC. The lower value of $\mathrm{K}^{\text {trans }}$ indicates the 
histological grades of HCC, and the values of $\mathrm{K}_{\mathrm{ep}}$ and $\mathrm{V}_{\mathrm{e}}$ have proved to be significantly related to the tumor microvascular density. There is no difference among these DCE-MRI deprived parameters for discriminating low- from high-grade HCC in terms of their performance. This means that DCE-MRI using gadoxetic acid has great potential for the qualitative assessment of tumor neoangiogenesis and aggressiveness of $\mathrm{HCC}^{[23]}$.

\section{RESTRICTED DIFFUSION MOVEMENT OF WATER MOLECULES WITHIN TUMOR CELLS}

HCC is easier to recognize pathologically because of its distinctive cytological atypia and architectural abnormalities compared with other cirrhotic nodules ${ }^{[24]}$. The early HCC nodule is well differentiated with an indistinct appearance, while HCC nodules that have progressed are mostly moderately differentiated with a distinct pattern and often, with a more disordered cellular structure ${ }^{[25,26]}$.

DWI is a noninvasive technique for visualizing the $3 \mathrm{D}$ microscopic movement of water molecules within cells to provide information regarding physiological tissue characteristics. HCC and other cancers usually possess higher cellularity, tissue disorganization, and less extracellular space, resulting in impedance of water diffusion; therefore, DWI shows a high-intensity signal ${ }^{[27,28]}$. In the past few years, many studies have investigated the apparent diffusion coefficient (ADC) value of DWI in predicting the differentiation of HCC $^{[29-31]}$. The conclusions however, were not consistent. This might be due to the fact that DWI cannot simply reflect the diffusion of water molecules in living tissues and capillary perfusion affects the stability of DWI performance as well.

Intravoxel incoherent motion (IVIM), as a DWI-derived novel technique, enables monitoring of tissue diffusivity and microcapillary perfusion independently ${ }^{[32]}$. IVIM-derived parameters such as perfusion fraction (fp) and diffusion coefficient (D) combined with ADC of DWI, are reported to correlate with HCC histological grade ${ }^{[33-35]}$. In the study by Granata et al. ${ }^{[33]}$, ADC $\left(2.11 \times 10^{-3} \mathrm{~mm}^{2} / \mathrm{s}\right)$, fp $(47.33 \%)$ and D $\left(0.94 \times 10^{-3} \mathrm{~mm}^{2} / \mathrm{s}\right)$ values were considered as the optimal cut-off points in distinguishing high- from lowgrade HCCs. However, the study only included Edmondson-Steiner grade 1 to 3 HCC nodules and did not include Edmondson-Steiner grade 4 HCC, which made identification of high-grade HCCs non specific. Woo et al. ${ }^{[34]}$, explored the relationship of ADC and D values with the histological grade of HCC. The results showed that there was a significant negative correlation between ADC and D values with the histologic grade of HCC. Moreover, the D value had better diagnostic performance than the ADC value for differentiating low- and high-grade HCC. Similar results were reported by Sokmen et al. ${ }^{[35]}$, Therefore, both studies improved the design of the experiments, and further confirmed the results on the basis of the findings by Granata et al ${ }^{[33]}$, which indicated that the combination of DWI and IVIM could be used to determine the degree of HCC differentiation rather than using DWI alone. However, due to defects in the study design (i.e., retrospective study), insufficient sample size and an unclear gold standard, further prospective studies are needed.

Diffusion kurtosis imaging (DKI) is an attempt to provide a more accurate model of diffusion, and to reflect tissue heterogeneity in non-Gaussian diffusion behavior ${ }^{[36]}$. Recently, our team validated the performance of DKI in predicting the degree of differentiation of $\mathrm{HCC}^{[37]}$. The results showed that mean apparent kurtosis coefficient (MK) and ADC values are significantly correlated with the grade of HCC [Figure 1]. In addition, the MK value represents a higher specificity than the ADC in differentiating high-grade from low-grade HCCs. We speculated that this might be due to the fact that increased tumor cellularity results in decreased extracellular space and the restricted diffusion of water molecules, which is visually presented as decreased $\mathrm{ADC}$ and MD in higher-grade HCC. Furthermore, a higher MK value may be an independent risk factor for early tumor recurrence and poor prognosis in HCC patients, which might be related to the higher-grade of HCC that often tend to be more proliferative, aggressive and heterogeneous, and result in a more irregular tumor microstructure ${ }^{[38]}$. 

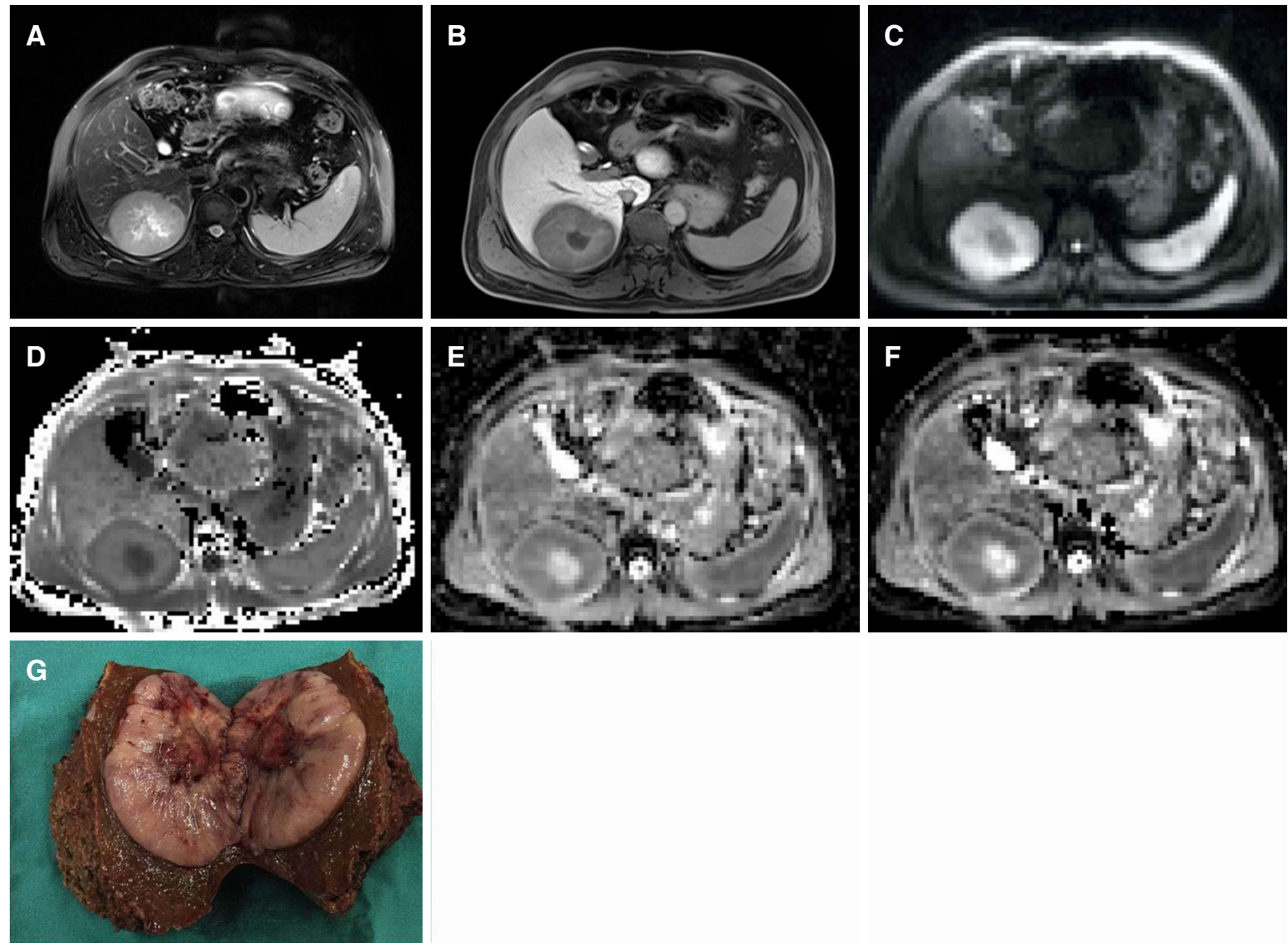

Figure 1. A 48-year-old male with a pathologically confirmed $\mathrm{HCC}$ with $\mathrm{MVI}$. A $7.8 \mathrm{~cm} \times 6.0 \mathrm{~cm}$ tumor in the right posterior hepatic section shows slight hyperintensity on T2-weighted image (A), hypo-intensity relative to the surrounding liver parenchyma in hepatobiliary phase (B), and restricted diffusion on the DWI with a b-value of $700 \mathrm{~s} / \mathrm{mm}^{2}$ (C). MK map (D) shows higher signal intensity of tumor compared with that of background liver parenchyma. ADC (E) and MD (F) maps show lower signal intensity compared with that of liver parenchyma. The calculated mean values of MK, ADC, and MK for the tumor were $0.99,1.10 \times 10^{-3} \mathrm{~mm}^{2} / \mathrm{s}$, and $1.28 \mathrm{~mm}^{2} / \mathrm{s}$, respectively. The pathological results after tumor resection demonstrated HCC [Edmondson-Steiner (III) with positive MVI (G)]. HCC: hepatocellular carcinoma; DWI: diffusion-weighted imaging; ADC: apparent diffusion coefficient; MD: mean diffusion; MK: mean apparent kurtosis coefficient

MRE is a noninvasive imaging technology for measuring the viscoelastic properties of the liver, and is reported to be capable of quantitatively assessing tumor stiffness, in addition to effectively identifying focal liver lesions ${ }^{[39]}$. A preliminary study reported that tumor stiffness detected by MRE might be able to differentiate HCC tumor grade ${ }^{[40]}$. However, further research is needed to verify the value of MRE in determining the degree of HCC differentiation.

\section{DECREASED UPTAKE OF LIVER-SPECIFIC CONTRAST AGENTS}

Kupffer cells, a type of macrophage that reside in the sinusoidal endothelial cells of the liver, are more likely to be distributed in early-stage or well-differentiated HCC than advanced $\mathrm{HCC}^{[41,42]}$. In addition, approximately half of the administered dose of gadoxetic acid, a hepatobiliary contrast agent, is taken up by hepatocytes through the organic anionic transporting polypeptide (OATP) family and subsequently excreted into bile ${ }^{[43]}$. Since there is progressive depletion of OATP with dedifferentiation, moderate to poorly differentiated tumors do not take up gadoxetate, and thus appear hypointense on hepatobiliary phase (HBP) of MRI.

Based on the above physiological mechanisms, liver-specific contrast agents such as superparamagnetic iron-oxide nanoparticles (SPION) and gadolinium-ethoxy benzyl-diethylenetriamine penta-acetic acid 
(Gd-EOB-DTPA) have been produced and used in HCC diagnosis and characterization. However, SPIONenhanced MRI has lower sensitivity than Gd-EOB-DTPA-enhanced MRI, especially for early HCCs without early enhancement; thus, SPION-enhanced MRI is rarely used as the contrast agent of choice in Western countries. However, SPION-enhanced MRI is still used in the East as a means of evaluating treatment response in $\mathrm{HCC}^{[44]}$.

Decreased expression levels of OATP during multi-step hepatocarcinogenesis are inversely correlated with HCC tumor grade and aggressiveness ${ }^{[45,46]}$. However, some well-differentiated HCCs and approximately $5 \%-12 \%$ of moderately differentiated HCCs overexpress OATP8, which is thought to be associated with a genetic alteration or of a different cellular origin ${ }^{[45]}$. A consensus report has been reached on the application and prospects of developing Gd-EOB-DTPA enhanced MRI for the early diagnosis, follow-up and outcome monitoring of HCC patients ${ }^{[47]}$. The report indicated that hypervascularity on the arterial phase and the low signal on HBP images of Gd-EOB-DTPA-enhanced MRI is more sensitive to the diagnosis of HCC when compared with CT. Moreover, HBP imaging provides critical information during the follow-up of cirrhosisrelated nodules, especially for those with a diameter less than $2 \mathrm{~cm}$, for predicting the histological grade of the tumor ${ }^{[46,48]}$. The above research suggests that functional MRI technologies, especially the HBP scan of Gd-EOB-DTPA-enhanced-MRI, will gradually become an essential means for predicting the differentiation of tumors and precise characterization of HCC.

\section{FDG CONCENTRATION}

The upregulation of glycogen metabolism is a prominent feature of tumor cells and it promotes survival, proliferation, and resistance to antitumor therapy ${ }^{[49]}$. Previous studies have identified that aberrant tumor cell metabolism was associated with the expression of genes encoding enzymes leading to glycogen metabolic reprogramming and promoting HCC progression ${ }^{[50]}$.

Uptake of fluorine-18 FDG ( ${ }^{18} \mathrm{~F}$-FDG) based on increased glucose metabolism in tumor cells is considered as a sensitive indicator of tumor viability ${ }^{[51]}$. PET imaging provides the metabolic status of tumor tissues with high sensitivity and specificity. Therefore, ${ }^{18} \mathrm{~F}-\mathrm{FDG} / \mathrm{PET}$, as a product of the combination of the above two mechanisms, is often used as an effective means for tumor characterization and evaluation of tumor response. Standardized uptake value, a semi-quantitative index of FDG/PET, is reported to be related to HCC-histological grade and poor prognosis of patients, with poorly differentiated or high-grade tumors showing higher intensities on FDG-PET ${ }^{[52]}$. Moreover, the advent of novel radiopharmaceuticals recently such as ${ }^{11} \mathrm{C}$-choline has improved the diagnostic performance of $\mathrm{HCC}$ characterization and tumor grade assessment ${ }^{[53]}$.

In comparison with PET/CT, PET/MRI shows a higher sensitivity for displaying composition and structure of tissues. PET/MRI in combination with DWI has an advantage in the differentiation of tumor tissue from non-tumor liver parenchyma, and is also helpful for understanding tumor characteristics ${ }^{[54]}$. However, FDG-PET/MRI is mostly limited to the diagnosis of HCC and research on the value of FDG-PET MRI in predicting poor differentiation and prognosis of HCC is still lacking.

\section{MVI}

MVI is typically correlated with aggressive biological behaviors of HCC, and is generally considered as a risk factor for early recurrence of HCC in patients ${ }^{[55]}$. Tumor characteristics, such as a larger diameter and tumor size, multiple lesions, incomplete capsule, and an irregular tumor margin, can be used as biomarkers in predicting the presence of $\mathrm{MVI}^{[5,57]}$. Moreover, significantly increased serum levels of parameters such as $\alpha$-fetoprotein, PIVKA-II, and cytokines (e.g., interleukin-35, phospho-beta1 integrin, transforming growth factor-beta1, p-Smad-2, and E-cadherin) suggest the possibility of $\mathrm{MVI}^{[58-61]}$. 
Multiple morphological imaging biomarkers including non-smooth tumor margins, irregular rim-like arterial phase hyperenhancement, tumor multifocality, and "mosaic" architecture, are reported to be highly correlated with MVI in HCC ${ }^{[62-64]}$. DWI and its-derived technologies have also shown great potential in detecting MVI in HCC. The mean and minimum ADC values of HCCs with MVI are reported to be lower than those of HCCs without MVI ${ }^{[65]}$. In addition, a higher MK value on DKI and irregular rim enhancement pattern are highly correlated with the presence of $\mathrm{MVI}^{[66]}$. Similar results were reported in our previous study $^{[37]}$ [Figure 1]. The mechanism underlying these results may be associated with the formation of a more complex microenvironment induced by MVI, such as the presence of tumor cell proliferation, necrosis, or inflammatory damage ${ }^{[67]}$. Therefor, a greater packed cell structure and more irregular, heterogeneous environments are likely to occur in HCC with MVI, resulting in increased tissue diffusion, which manifest as increased $\mathrm{MK}^{[6,68]}$. Furthermore, hypo-intensity on HBP images on Gd-EOB-DTPA enhanced-MRI in conjunction with other clinical indicators has been proven to further improve the prediction of MVI in HCC, and is superior in predicting early recurrence and the survival rate in HCC patients ${ }^{[69,70]}$.

AI, a branch of computer science, has emerged as a new technology to study and develop the theory, technology and application systems for simulating, extending and expanding human intelligence. In recent years, AI has had huge potential in medical imaging and attracted considerable attention in a range of fields from tumor diagnosis to outcomes prediction. Radiomics, and its derived analyses such as texture analysis, are noninvasive methods for the prediction of tumor heterogeneity, and have shown favorable predictive accuracy of MVI status in patients with $\mathrm{HCC}^{[71-74]}$. Radiomics signatures associated with tumor size and intra-tumoral heterogeneity were reported to be the top-ranked indicators for MVI prediction. In addition, a radiomics nomogram incorporated with the clinical and radiological features outperform the combination of clinical and radiological features for predicting MVI and the clinical outcomes of HCC patients ${ }^{[73]}$.

\section{INTRACELLULAR FAT ACCUMULATION}

Intracellular fat accumulation, a common morphological characteristic of HCC, occurs in the context of ischemia and hypoxia dueto decreased portal vein and nontumoral artery flow, and insufficient unpaired $\operatorname{arteries}^{[75]}$. Thus, intracellular fat accumulation is gradually increased in low-grade dysplastic nodules, highgrade dysplastic nodules, and early-stage $\operatorname{HCC}^{[76,77]}$. However, with regard to intra-tumoral fatty infiltration in poorly differentiated HCC, controversy exists ${ }^{[75,78]}$.

Chemical-shift MRI is the most commonly used technique to monitor the presence of intra-tumoral fat infiltration [Figure 2]. There is a close relationship between intracellular fatty change and MVI in HCC. MVI is more likely to occur in non-containing fatty HCCs, which means intra-tumoral fat infiltration suggests a lower risk for MVI in HCC $^{[79]}$. Moreover, Kubota et al. ${ }^{[80]}$, reported that macro-vesicular steatosis HCC has a better prognosis with less portal vein invasion and a lower cumulative risk of recurrence than microvesicular steatosis HCC. More related research is necessary for detecting intra-tumoral fat infiltration, and predicting the prognosis of HCC with different histopathological characteristics in the early stage of hepatocarcinogenesis, so as to optimize disease management and promote personalized treatment.

\section{INVASIVE GROWTH PATTERN}

Invasive growth, defined as the invasion of cancer cells into adjacent tissues and the vascular lymphatic system, is correlated with tumor metastasis and poor prognosis. Aberrant regulation of cell migration contributes to the progression of cancer cell invasion ${ }^{[81]}$.

Tumors with a permeative growth pattern on CT/MRI images are frequently termed "infiltrative", which manifest as lesions with indistinguishable margins on CT/MRI images. The Liver Imaging Reporting and Data System was developed to standardize the interpretation, reporting, and evaluation of patients at risk of developing HCC, and provides an explicit interpretation of the features of "infiltrative appearance" in 

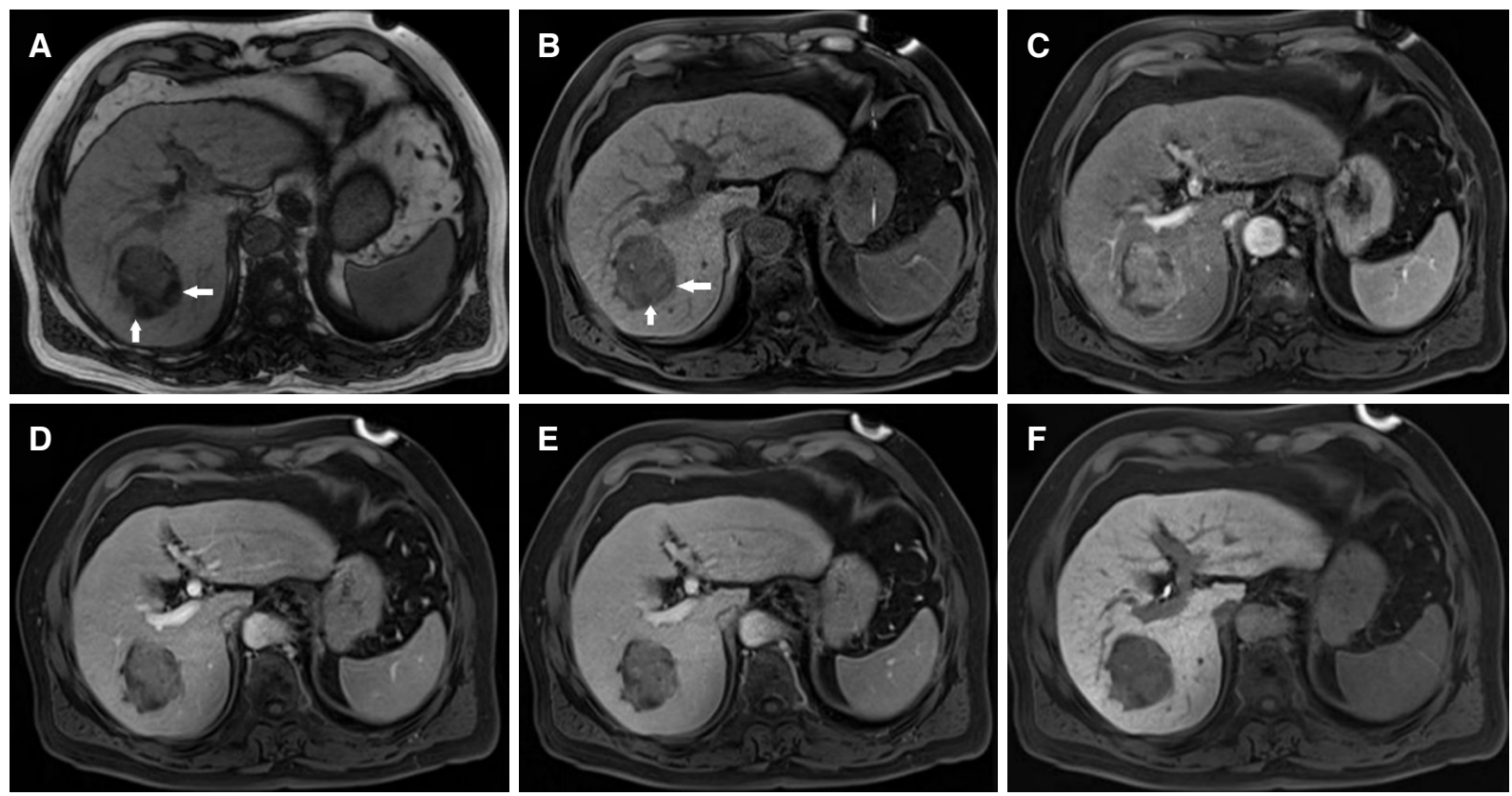

Figure 2. A 54-year-old female with hepatocellular carcinoma in segment VII of the liver. The 4.2-cm-sized mass shows focal fatty infiltration (white arrows) on opposed phase image (A) and unenhanced T1-weighted image (B), marked enhancement in arterial phase (C), wash-out appearance in portal venous phase (D) and delay phase (E), and hypo-intensity on 20 min hepatobiliary phase (F)

the latest version. It classifies a mass with infiltrative appearance as LR-M, which is probably or definitely malignant but not HCC specific. As the majority of tumors with infiltrative appearance in at-risk patients are HCC, the description of "infiltrative" is likely to indicate HCC in practice ${ }^{[82]}$. Portal vein tumor thrombosis is the most helpful clue in the identification of infiltrative HCC, with accuracy ranging from $68 \%$ to $100 \%$. The characteristic imaging manifestation of portal vein tumor thrombosis is the solid mass in the vascular cavity, which has similar enhancement features to the tumor itself on triphasic dynamic contrast-enhanced CT scan, especially with arterial phase enhancement and wash-out in the portal venous phase $\mathrm{e}^{[83,84]}$. Clinically, it is vital to distinguish portal vein tumor thrombosis and portal vein thrombus accurately for the intervention and treatment of patients with $\mathrm{HCC}^{[85]}$. Imaging provides key evidence that portal vein thrombus is not enhanced in the arterial phase and occasionally, disappears after anticoagulant therapy ${ }^{[86]}$. An ill-defined mass with heterogeneous attenuation/signal intensity is also highly indicative of the presence of an infiltrative growth pattern, which is pathologically characterized by the fusion of tumor tissue with liver parenchyma ${ }^{[87]}$.

\section{BILE DUCT INVASION OR TUMOR THROMBOSIS}

HCC with bile duct invasion has a poorer prognosis since these lesions are frequently associated with obstructive jaundice, cholangitis, and biliary bleeding, in addition to portal vein thrombosis ${ }^{[88-90]}$. Imaging characteristics are often used to indicate the presence of tumor thrombosis in the bile duct, including a soft tissue mass with proximal bile duct dilatation and a similar enhancement pattern to HCC, since there is a possibility of necrosis and bleeding ${ }^{[91]}$. Tumor thrombi are characterized as a filling defect in the bile duct, unexpected obstruction of the bile duct, and cholangiectasis in MR cholangiopancreatography; however, the diagnosis of both bile duct and portal vein microthrombi remains difficult ${ }^{[92]}$. Moreover, HCC with bile duct thrombi are poorly differentiated, unencapsulated, and invasive ${ }^{[93]}$. These findings indicate that the timely diagnosis of bile duct invasion is crucial for the management of HCC patients.

\section{TUMOR SPREAD AND METASTASIS}

Tumor metastasis accounts for the main cause of death in some cancer patients. A central pivot event of this process is the start-up of a program termed the epithelial-mesenchymal transition, which plays an important 
Table 3. Genetics, molecular pathology and histopathology markers related to poor prognosis in HCC

\begin{tabular}{|c|c|c|}
\hline Biomarkers & Role in occurrence, development and prognosis of HCC & Imaging biomarkers \\
\hline CTNNB1 & $\begin{array}{l}\text { Its mutation accounts for } 20 \%-40 \% \text { of HCC; play pivotal role in } \\
\text { the poor prognosis of HCC; HCCs with CTNNB1 mutations show } \\
\text { a higher grade of differentiation with frequent pseudoglandular } \\
\text { patterns and bile production. The subgroup of hepatocellular } \\
\text { adenomas with an active } \beta \text {-catenin gene show high probability of } \\
\text { malignant transformation }\end{array}$ & $\begin{array}{l}\text { A high enhancement ratio on HBP images of Gadoxetic acid- } \\
\text { enhanced-MRI; a high value of ADC on DWI images }\end{array}$ \\
\hline $\mathrm{Ki}-67$ & $\begin{array}{l}\text { Highly correlated with staging, grading and recurrence rate } \\
\text { of HCC; high possibility of adverse pathological features and } \\
\text { invasive behaviors }\end{array}$ & $\begin{array}{l}\text { The parameter } \mathrm{K}^{\text {trans }} \text { of free-breathing DCE-MRI using gadoxetic } \\
\text { acid; T1 rt- } 20 \text { min, tumor-to-muscle SI ratio, ADC value, and } \\
\text { arterial inhomogeneous enhancement on gadoxetic acid- } \\
\text { enhanced MRI; texture analysis on gadoxetic acid-enhanced-MRI }\end{array}$ \\
\hline CK-19 & $\begin{array}{l}\text { Correlated with some clinicopathological features of tumors such } \\
\text { as poor differentiation, metastasis, and early recurrence after } \\
\text { resection and radiofrequency ablation }\end{array}$ & $\begin{array}{l}\text { The arterial rim enhancement, targetoid appearance, non- } \\
\text { peripheral "washout", and irregular tumor margin on gadoxetic } \\
\text { acid-enhanced MRI; lower tumor-to-liver ADC ratio, and lower } \\
\text { tumor-to-liver SI ratio at HBP images }\end{array}$ \\
\hline EpCAM & $\begin{array}{l}\text { Involved in a series of biological processes such as cell } \\
\text { proliferation; the overexpression of EpCAM is correlated with the } \\
\text { angiogenesis and poor outcome of HCC; in addition, EpCAM- } \\
\text { positive HCC is considered to be a subtype of human HCC with a } \\
\text { poor prognosis }\end{array}$ & $\begin{array}{l}\text { No significant correlation between irregular rim-like } \\
\text { hyperenhancement on gadoxetic acid-enhanced-MRI and } \\
\text { EpCAM status in HCC. Whether imaging markers can be used to } \\
\text { indicate the EpCAM positive HCC is still unclear }\end{array}$ \\
\hline
\end{tabular}

HCC: hepatocellular carcinoma; CTNNB1: $\beta$-catenin; HBP: hepatobiliary phase; Gd-EOB-DTPA: gadolinium-ethoxy benzyldiethylenetriamine penta-acetic acid; MRI: magnetic resonance imaging; ADC: apparent diffusion coefficient; DWI: diffusion-weighted imaging; SI: signal intensity; CK-19: cytokeratin-19 (CK-19); EpCAM: epithelial cell adhesion molecule

regulatory role in embryogenesis.

Treatment approaches for cancer are largely depended on both the stage of disease at diagnosis, and the patient's performance status ${ }^{[94]}$. Therefore, early detection of tumor spread or metastasis allows for the most appropriate treatment plans and to strive for more survival opportunities for HCC patients. Contrast-enhanced CT or MRI ensure implementation of one-step inspection and display the distinct enhancement features of metastasis better compared to ultrasound ${ }^{[12]}$. MRI with liver-specific contrast agents improves diagnostic efficiency in the early identifification of intrahepatic micrometastasis, as well as follow-up surveillance of disease development and outcomes ${ }^{[95]}$. PET/CT has emerged as a useful modality in diagnosing extrahepatic lesions in patients with advanced HCC and assessing tumor grading ${ }^{[96,97]}$. Furthermore, newly developed dual-tracer PET/CT improve and complement the advantages compared to single-tracer imaging in the evaluation of HCC metastasis, and has gradually become an alternative modality to PET/CT for detecting extrahepatic metastasis in HCC patients ${ }^{[98]}$.

\section{FACTORS RELATED TO GENETICS, MOLECULAR PATHOLOGY AND IMMUNOHISTOCHEMISTRY}

HCC is the result of a multifactorial, synergistic damage from various biological factors related to genetics, molecular pathology, and immunohistochemistry that impact upon HCC differentiation and prognosis. With the development of liver imaging technologies, some have been detected by imaging methods and proved to be associated with imaging biomarkers [Table 3].

\section{$\beta$-catenin mutation}

$\beta$-catenin (CTNNB1) has been recognized as the most frequently mutated oncogene during liver cancer. Its mutation accounts for around $20 \%-40 \%$ of all HCC cases, and is strongly associated with larger tumors, invasive growth, and vascular invasion. In addition, HCCs with the CTNNB1 mutation show a higher grade of differentiation with frequent pseudoglandular patterns and bile production ${ }^{[99]}$. Moreover, the subgroup of hepatocellular adenomas with an active $\beta$-catenin gene shows a high probability of malignant transformation $^{[100]}$. Recently, several studies reported that gadoxetic acid-enhanced-MRI could be used to detect the presence of CTNBB1 mutations in HCC, because the mutation of CTNNB1 would promote 
OATP expression ${ }^{[99,101]}$. The results showed that a high enhancement ratio on HBP images of Gadoxetic acidenhanced-MRI indicate the mutation of CTNBB1, and is closely associated with a higher differentiation grade of HCC. Moreover, a high value of ADC on DWI images could also be used as an indicator of HCC with the CTNBB1 mutation ${ }^{[101]}$.

\section{$\mathrm{Ki}-67$}

$\mathrm{Ki}-67$ is highly correlated with the staging, grading and recurrence of HCCs. The overexpression of Ki67 indicates a high possibility of adverse pathological features and invasive behaviors of the tumor ${ }^{[102]}$. The parameter $\mathrm{K}^{\text {trans }}$ of free-breathing DCE-MRI using gadoxetic acid is reported to be highly associated with Ki67 proliferation status, and the lower value of $\mathrm{K}^{\text {trans }}$ indicate higher Ki-67 indices and histological grades of $\mathrm{HCC}^{[103]}$. In addition, the T1 rt-20 min, tumor-to-muscle signal intensity ratio, ADC value and the arterial inhomogeneous enhancement pattern on gadoxetic acid-enhanced-MRI are also correlated with high-Ki-67 expression ${ }^{[104-106]}$. Furthermore, texture analysis, on the basis of gadoxetic acid-enhanced-MRI, can be applied as a tentative approach to preoperatively predict the Ki-67 status of HCC after curative resection ${ }^{[107]}$.

\section{Cytokeratin-19}

Cytokeratin-19 (CK-19) are important keratin proteins expressed in liver tissue and show differential expression at different stages of physiological development of the liver. The expression of CK-19 is correlated with some clinicopathological features of tumor such as poor differentiation, metastasis, and early recurrence after tumor resection or radiofrequency ablation ${ }^{[108]}$. The arterial rim enhancement, targetoid appearance, non-peripheral "washout", and irregular tumor margins on gadoxetic acid-enhanced MRI are reported to be effective imaging markers for evaluating the CK-19 status of $\mathrm{HCC}^{[109-112]}$. Moreover, lower tumor-to-liver ADC and signal intensity ratios in HBP images may be helpful for predicting CK19-positive HCC with early recurrence ${ }^{[112]}$.

\section{Epithelial cell adhesion molecule}

Epithelial cell adhesion molecule (EpCAM) is a membrane glycoprotein expressed in most normal epithelial cells, and has been proven to be involved in a series of biological processes such as cell proliferation ${ }^{[113]}$. It has been reported that the overexpression of EpCAM is closely correlated with the angiogenesis and poor outcomes in $\mathrm{HCC}^{[114]}$. In addition, EpCAM-positive HCC is also considered to be a subtype of human HCC with a poor prognosis ${ }^{[115]}$. However, the imaging biomarkers that can be used to reflect EpCAM-positive status in HCC have not been described. Recently, Rhee et al ${ }^{[63]}$, used the imaging feature of irregular rimlike hyperenhancement as the poor prognostic index to explore the value of gadoxetic acid-enhanced MRI in predicting the overexpression of immunomarkers including EpCAM. However, results showed there is no statistically significant association between irregular rim-like hyperenhancement and EpCAM status in HCC. Therefore, whether imaging markers can be used to indicate EpCAM positive HCC is still unclear.

\section{CONCLUSION}

Hepatocarcinogenesis is a progressive and multi-stage process of molecular heterogeneity and histological dedifferentiation. The poor prognosis of HCC is strongly associated with the presence of aggressive biological behaviors in tumors. Modern noninvasive imaging technologies such as CEUS, DEC-CT/MRI and PET imaging improve the efficiency of early identification, characterization and assessment of HCC, and have been widely used for screening, diagnosis, and improving the survival of HCC patients. The increasing use of multiparametric functional methods, including DWI and its derived-technologies (IVIM, DKI), contrast enhanced-MRI with SPION or Gd-EOB-DTPA, MRE, chemical-shift MRI, radiomics and AI, for assessing tumor morphology, vascularity, cellularity, metabolic capability, texture, radiomics features, OATP function, and Kupffer cell function, thereby providing early, accurate and reliable evidence of the aggressive biological behaviors of HCC is most encouraging for clinicians and radiologists. Although liver imaging has obvious advantages in identifying the poor prognosis of HCC, currently, there is no doubt that multidisciplinary 
management, including radiology, genetics, molecular pathology and histopathology would result in a more accurate and reliable diagnosis for predicting the prognosis of HCC.

\section{DECLARATIONS}

\section{Authors' contributions}

Made substantial contributions to the conception and design of the study, and performed data analysis and interpretation: Zhang Y, Huang ZX, Chen J

Performed data acquisition, as well as provided administrative, technical, and material support: Shi YJ, Jiang HY, Cao LK, Song B

\section{Availability of data and materials}

Not applicable.

\section{Financial support and sponsorship}

This work was supported by grants from the Research Grant of National Nature Science Foundation of China (Grant number 81771797), Science and Technology Support Program of Sichuan Province (Grant number 2017SZ0003), and the 1.3.5 project for disciplines of excellence, West China Hospital, Sichuan University (Grant number ZYJC18008).

\section{Conflicts of interest}

All authors declared that there are no conflicts of interest.

\section{Ethical approval and consent to participate}

Not applicable.

\section{Consent for publication}

Not applicable.

\section{Copyright}

(c) The Author(s) 2020.

\section{REFERENCES}

1. Bray F, Ferlay J, Soerjomataram I, Siegel RL, Torre LA, et al. Global cancer statistics 2018: GLOBOCAN estimates of incidence and mortality worldwide for 36 cancers in 185 countries. Int J Cancer 2018;68:394-424.

2. Selcuk H. Prognostic factors and staging systems in hepatocellular carcinoma. Exp Clin Transplant 2017;15:45-9.

3. Farinati F, Vitale A, Spolverato G, Pawlik TM, Huo TL, et al. Development and Validation of a new prognostic system for patients with hepatocellular carcinoma. PLoS Med 2016;13:e1002006.

4. Rodríguez-Perálvarez M, Luong TV, Andreana L, Meyer T, Dhillon AP, Burroughs AK. A systematic review of microvascular invasion in hepatocellular carcinoma: diagnostic and prognostic variability. Ann Surg Oncol 2013;20:325-9.

5. Sohn JH, Duran R, Zhao Y, Fleckenstein F, Chapiro J, et al. Validation of the Hong Kong liver cancer staging system in determining prognosis of the North American patients following intra-arterial therapy. Clin Gastroenterol Hepatol 2017;15:746-55.e4.

6. Martins-Filho SN, Paiva C, Azevedo RS, Alves VAF. Histological grading of hepatocellular carcinoma-a systematic review of literature. Front Med (Lausanne) 2017;10:193.

7. Degasperi E, Colombo M. Distinctive features of hepatocellular carcinoma in non-alcoholic fatty liver disease. Lancet Gastroenterol Hepatol 2016;1:156-64.

8. Coskun M. Hepatocellular carcinoma in the cirrhotic liver: evaluation using computed tomography and magnetic resonance imaging. Exp Clin Transplant 2017;15:36-44.

9. Yoneda N, Matsui O, Kobayashi S, Kitao A, Kozaka K, et al. Current status of imaging biomarkers predicting the biological nature of hepatocellular carcinoma. Jpn J Radiol 2019;37:191-208.

10. Hu HT, Shen SL, Wang Z, Shan QY, Huang XW, et al. Peritumoral tissue on preoperative imaging reveals microvascular invasion in hepatocellular carcinoma: a systematic review and meta-analysis. Abdom Radiol (NY) 2018;43:3324-30.

11. Ayuso C, Rimola J, Vilana R, Burrel M, Darnell A, et al. Diagnosis and staging of hepatocellular carcinoma (HCC): current guidelines. Eur J Radiol 2018;101:72-81 
12. Schelhorn J, Best J, Dechêne A, Göbel T, Bertram S, et al. Evaluation of combined Gd-EOB-DTPA and gadobutrol magnetic resonance imaging for the prediction of hepatocellular carcinoma grading. Acta Radiologica 2016;57:932-8.

13. Navin PJ, Venkatesh SK. Hepatocellular carcinoma: state of the art imaging and recent advances. J Clin Transl Hepatol 2019;7:72-85.

14. Jiang T, Zhu AX, Sahani DV. Established and novel imaging biomarkers for assessing response to therapy in hepatocellular carcinoma. J Hepatol 2013;58:169-77.

15. Clark T, Maximin S, Meier J, Pokharel S, Bhargava P. Hepatocellular carcinoma: review of epidemiology, screening, imaging diagnosis, response assessment, and treatment. Curr Prob Diagn Radiol 2015;44:479-86.

16. Oishi K, Itamoto T, Amano H, Fukuda S, Ohdan H, et al. Clinicopathologic features of poorly differentiated hepatocellular carcinoma. J Surg Oncol 2007;95:311-6.

17. Himeno H, Enzan H, Saibara T, Onishi S, Yamamoto Y. Hitherto unrecognized arterioles within hepatocellular carcinoma. J Pathol 1994;174:217-22.

18. Hayashi M, Matsui O, Ueda K, Kawamori Y, Gabata T, et al. Progression to hypervascular hepatocellular carcinoma: correlation with intranodular blood supply evaluated with CT during intraarterial injection of contrast material. Radiology 2002;225:143-9.

19. Ye XD, Yuan Z, Zhang J, Yuan Z. Radiological biomarkers for assessing response to locoregional therapies in hepatocellular carcinoma: From morphological to functional imaging (Review). Oncol Rep 2017;37:1337-46.

20. Feng Y, Qin XC, Luo Y, Li YZ, Zhou X. Efficacy of contrast-enhanced ultrasound washout rate in predicting hepatocellular carcinoma differentiation. Ultrasound Med Biol 2015;41:1553-60.

21. Lassau N, Koscielny S, Chami L, Chebil M, Benatsou B, et al. Advanced hepatocellular carcinoma: early evaluation of response to bevacizumab therapy at dynamic contrast-enhanced US with quantification--preliminary results. Radiology 2011;258:291-300.

22. Mann CD, Neal CP, Garcea G, Manson MM, Dennison AR, et al. Prognostic molecular markers in hepatocellular carcinoma: a systematic review. Eur J Cancer 2007;43:979-92.

23. Chen J, Chen C, Xia C, Huang Z, Zuo P, et al. Quantitative free-breathing dynamic contrast-enhanced MRI in hepatocellular carcinoma using gadoxetic acid: correlations with Ki67 proliferation status, histological grades, and microvascular density. Abdom Radiol (NY) 2018;43:1393-403.

24. Jiang K, Al-Diffhala S, Centeno BA. Primary liver cancers-part 1: histopathology, differential diagnoses, and risk stratification. Cancer Control 2018;25:1073274817744625.

25. Park YN, Kim MJ. Hepatocarcinogenesis: imaging-pathologic correlation. Abdom Imaging 2011;36:232-43.

26. International Consensus Group for Hepatocellular NeoplasiaThe International Consensus Group for Hepatocellular Neoplasia. Pathologic diagnosis of early hepatocellular carcinoma: a report of the international consensus group for hepatocellular neoplasia. Hepatology 2009;49:658-64

27. Calistri L, Castellani A, Matteuzzi B, Mazzoni E, Pradella S, et al. Focal liver lesions classification and characterization: what value do DWI and ADC have? J Comput Assist Tomogr 2016;40:701-8.

28. Di Pietropaolo M, Briani C, Federici GF, Marignani M, Begini P, et al. Comparison of diffusion-weighted imaging and gadoxetic acidenhanced MR images in the evaluation of hepatocellular carcinoma and hypovascular hepatocellular nodules. Clin Imaging 2015;39:46875.

29. Nasu K, Kuroki Y, Tsukamoto T, Nakajima H, Mori K, et al. Diffusion-weighted imaging of surgically resected hepatocellular carcinoma: imaging characteristics and relationship among signal intensity, apparent diffusion coefficient, and histopathologic grade. AJR Am J Roentgenol 2009;193:438-44.

30. Heo SH, Jeong YY, Shin SS, Kim JW, Lim HS, et al. Apparent diffusion coefficient value of diffusion-weighted imaging for hepatocellular carcinoma: correlation with the histologic differentiation and the expression of vascular endothelial growth factor. Korean J Radiol 2010;11:295-303.

31. Nakanishi M, Chuma M, Hige S, Omatsu T, Yokoo H, et al. Relationship between diffusion-weighted magnetic resonance imaging and histological tumor grading of hepatocellular carcinoma. Ann Surg Oncol 2012;19:1302-9.

32. Li YT, Cercueil JP, Yuan J, Chen W, Loffroy R, et al. Liver intravoxel incoherent motion (IVIM) magnetic resonance imaging: a comprehensive review of published data on normal values and applications for fibrosis and tumor evaluation. Quant Imaging Med Surg 2017;7:59-78.

33. Granata V, Fusco R, Catalano O, Guarino B, Granata F, et al. Intravoxel incoherent motion (IVIM) in diffusion-weighted imaging (DWI) for Hepatocellular carcinoma: correlation with histologic grade. Oncotarget 2016;7:79357-64.

34. Woo S, Lee JM, Yoon JH, Joo I, Han JK, et al. Intravoxel incoherent motion diffusion-weighted MR imaging of hepatocellular carcinoma: correlation with enhancement degree and histologic grade. Radiology 2014;270:758-67.

35. Sokmen BK, Sabet S, Oz A, Server S, Namal E, et al. Value of intravoxel incoherent motion for hepatocellular carcinoma grading. Transplant Proc 2019;51:1861-6.

36. Wu EX, Cheung MM. MR diffusion kurtosis imaging for neural tissue characterization. NMR Biomed 2010;23:836-48.

37. Cao L, Chen J, Duan T, Wang M, Jiang H, et al. Diffusion kurtosis imaging (DKI) of hepatocellular carcinoma: correlation with microvascular invasion and histologic grade. Quant Imaging Med Surg 2019;9:590-602.

38. Jensen JH, Helpern JA. MRI quantification of non-Gaussian water diffusion by kurtosis analysis. NMR Biomed 2010;23:698-710.

39. Hennedige TP, Hallinan JT, Leung FP, Teo LL, Iyer S, et al. Comparison of magnetic resonance elastography and diffusion-weighted imaging for differentiating benign and malignant liver lesions. Eur Radiol 2016;26:398-406.

40. Thompson SM, Wang J, Chandan VS, Glaser KJ, Roberts LR, et al. MR elastography of hepatocellular carcinoma: correlation of tumor stiffness with histopathology features-Preliminary findings. Magn Reson Imaging 2017;37:41-5. 
41. Toth CA, Thomas P. Liver endocytosis and Kupffer cells. Hepatology 1992;16:255-66.

42. Choi BI, Takayasu K, Han MC. Small hepatocellular carcinomas and associated nodular lesions of the liver: pathology, pathogenesis, and imaging findings. AJR Am J Roentgenol 1993;160:1177-87.

43. Nassif A, Jia J, Keiser M, Oswald S, Modess C, et al. Visualization of hepatic uptake transporter function in healthy subjects by using gadoxetic acid-enhanced MR imaging. Radiology 2012;264:741-50.

44. Fukuda K, Mori K, Hasegawa N, Nasu K, Ishige K, et al. Safety margin of radiofrequency ablation for hepatocellular carcinoma: a prospective study using magnetic resonance imaging with superparamagnetic iron oxide. Jpn J Radiol 2019;37:555-63.

45. Kitao A, Matsui O, Yoneda N, Kozaka K, Shinmura R, et al. The uptake transporter OATP8 expression decreases during multistep hepatocarcinogenesis: correlation with gadoxetic acid enhanced MR imaging. Eur Radiol 2011;21:2056-66.

46. Kogita S, Imai Y, Okada M, Kim T, Onishi H, et al. Gd-EOB-DTPA-enhanced magnetic resonance images of hepatocellular carcinoma: correlation with histological grading and portal blood flow. Eur Radiol 2010;20:2405-13.

47. Zech CJ, Ba-Ssalamah A, Berg T, Chandarana H, Chau GY, et al. Consensus report from the 8th International Forum for Liver Magnetic Resonance Imaging. Eur Radiol 2020;30:370-82.

48. Huang K, Dong Z, Cai H, Huang M, Peng Z, et al. Imaging biomarkers for well and moderate hepatocellular carcinoma: preoperative magnetic resonance image and histopathological correlation. BMC Cancer 2019;19:364.

49. Zois CE, Harris AL. Glycogen metabolism has a key role in the cancer microenvironment and provides new targets for cancer therapy. J Mol Med (Berl) 2016;94:137-54.

50. Cervello M, Augello G, Cusimano A, Emma MR, Balasus D, et al. Pivotal roles of glycogen synthase-3 in hepatocellular carcinoma. Adv Biol Regul 2017;65:59-76.

51. Chen R, Li J, Zhou X, Liu J, Huang G. Fructose-1,6-bisphosphatase 1 reduces (18)F FDG uptake in hepatocellular carcinoma. Radiology 2017;284:844-53.

52. Seo S, Hatano E, Higashi T, Hara T, Tada M, et al. Fluorine-18 fluorodeoxyglucose positron emission tomography predicts tumor differentiation, P-glycoprotein expression, and outcome after resection in hepatocellular carcinoma. Clin Cancer Res 2007;13:427-33.

53. Castilla-Lievre MA, Franco D, Gervais P, Kuhnast B, Agostini H, et al. Diagnostic value of combining ${ }^{11} \mathrm{C}$-choline and ${ }^{18} \mathrm{~F}-\mathrm{FDG}$ PET/CT in hepatocellular carcinoma. Eur J Nucl Med Mol Imaging 2016;43:852-9.

54. Kong E, Chun KA, Cho IH. Quantitative assessment of simultaneous F-18 FDG PET/MRI in patients with various types of hepatic tumors: correlation between glucose metabolism and apparent diffusion coefficient. PLoS One 2017;12:e0180184.

55. Zhang X, Li J, Shen F. Significance of presence of microvascular invasion in specimens obtained after surgical treatment of hepatocellular carcinoma. J Gastroenterol Hepatol 2018;33:347-54.

56. Wu TH, Hatano E, Yamanaka K, Seo S, Taura K, et al. A non-smooth tumor margin on preoperative imaging predicts microvascular invasion of hepatocellular carcinoma. Surg Today 2016;46:1275-81.

57. Renzulli M, Buonfiglioli F, Conti F, Brocchi S, Serio I, et al. Imaging features of microvascular invasion in hepatocellular carcinoma developed after direct-acting antiviral therapy in HCV-related cirrhosis. Eur Radiol 2018;28:506-13.

58. Ma XL, Zhu J, Wu J, Tian L, Gao YY, et al. Significance of PIVKA-II levels for predicting microvascular invasion and tumor cell proliferation in Chinese patients with hepatitis B virus-associated hepatocellular carcinoma. Oncol Lett 2018;15:8396-404.

59. Zheng J, Seier K, Gonen M, Balachandran VP, Kingham TP, et al. Utility of serum inflammatory markers for predicting microvascular invasion and survival for patients with hepatocellular carcinoma. Ann Surg Oncol 2017;24:3706-14.

60. Long J, Guo H, Cui S, Zhang H, Liu X, et al. IL-35 expression in hepatocellular carcinoma cells is associated with tumor progression. Oncotarget 2016;7:45678-86.

61. Fransvea E, Mazzocca A, Antonaci S, Giannelli G. Targeting transforming growth factor (TGF)-betaRI inhibits activation of beta1 integrin and blocks vascular invasion in hepatocellular carcinoma. Hepatology 2009;49:839-50.

62. Chou CT, Chen RC, Lin WC, Ko CJ, Chen CB, et al. Prediction of microvascular invasion of hepatocellular carcinoma: preoperative CT and histopathologic correlation. AJR Am J Roentgenol 2014;203:W253-9.

63. Rhee H, An C, Kim HY, Yoo JE, Park YN, et al. Hepatocellular carcinoma with irregular rim-like arterial phase hyperenhancement: more aggressive pathologic features. Liver Cancer 2019;8:24-40.

64. Chernyak V, Fowler KJ, Kamaya A, Kielar AZ, Elsayes KM, et al. Liver imaging reporting and data system (LI-RADS) Version 2018: imaging of hepatocellular carcinoma in at-risk patients. Radiology 2018;289:816-30.

65. Zhao J, Li X, Zhang K, Yin X, Meng X, et al. Prediction of microvascular invasion of hepatocellular carcinoma with preoperative diffusion-weighted imaging: A comparison of mean and minimum apparent diffusion coefficient values. Medicine 2017;96:e7754.

66. Wang WT, Yang L, Yang ZX, Hu XX, Ding Y, et al. Assessment of microvascular invasion of hepatocellular carcinoma with diffusion kurtosis imaging. Radiology 2018;286:571-80.

67. Jensen JH, Helpern JA, Ramani A, Lu H, Kaczynski K. Diffusional kurtosis imaging: the quantification of non-gaussian water diffusion by means of magnetic resonance imaging. Magn Reson Med 2005;53:1432-40.

68. Ahn SJ, Kim JH, Park SJ, Kim ST, Han JK. Hepatocellular carcinoma: preoperative gadoxetic acid-enhanced MR imaging can predict early recurrence after curative resection using image features and texture analysis. Abdom Radiol (NY) 2019;44:539-48.

69. Lee S, Kim SH, Lee JE, Sinn DH, Park CK. Preoperative gadoxetic acid-enhanced MRI for predicting microvascular invasion in patients with single hepatocellular carcinoma. J Hepatol 2017;67:526-34.

70. Ryu T, Takami Y, Wada Y, Tateishi M, Hara T, et al. A clinical scoring system for predicting microvascular invasion in patients with hepatocellular carcinoma within the milan criteria. J Gastrointest Surg 2019;23:779-87.

71. Peng J, Zhang J, Zhang Q, Xu Y, Zhou J, et al. A radiomics nomogram for preoperative prediction of microvascular invasion risk in 
hepatitis B virus-related hepatocellular carcinoma. Diagn Interv Radiol 2018;24:121-7.

72. Xu X, Zhang HL, Liu QP, Sun SW, Zhang J, et al. Radiomic analysis of contrast-enhanced CT predicts microvascular invasion and outcome in hepatocellular carcinoma. J Hepatol 2019;70:1133-44.

73. Ji GW, Zhu FP. Radiomic features at contrast-enhanced CT predict recurrence in early stage hepatocellular carcinoma: a multiinstitutional study. Radiology 2020;294:568-79.

74. Zhu YJ, Feng B, Wang S, Wang LM, Wu JF, et al. Model-based three-dimensional texture analysis of contrast-enhanced magnetic resonance imaging as a potential tool for preoperative prediction of microvascular invasion in hepatocellular carcinoma. Oncol Lett 2019;18:720-32.

75. Kutami R, Nakashima Y, Nakashima O, Shiota K, Kojiro M. Pathomorphologic study on the mechanism of fatty change in small hepatocellular carcinoma of humans. J Hepatol 2000;33:282-9.

76. Takayama T, Makuuchi M, Hirohashi S, Sakamoto M, Okazaki N, et al. Malignant transformation of adenomatous hyperplasia to hepatocellular carcinoma. Lancet 1990;336:1150-3.

77. Villanueva A, Newell P, Chiang DY, Friedman SL, Llovet JM. Genomics and signaling pathways in hepatocellular carcinoma. Semin Liver Dis 2007;27:55-76.

78. Asayama Y, Nishie A, Ishigami K, Ushijima Y, Takayama Y, et al. Fatty change in moderately and poorly differentiated hepatocellular carcinoma on MRI: a possible mechanism related to decreased arterial flow. Clin Radiol 2016;71:1277-83.

79. Min JH, Kim YK, Lim S, Jeong WK, Choi D, et al. Prediction of microvascular invasion of hepatocellular carcinomas with gadoxetic acid-enhanced MR imaging: Impact of intra-tumoral fat detected on chemical-shift images. Eur J Radiol 2015;84:1036-43.

80. Kubota N, Ojima H, Hatano M, Yamazaki K, Masugi Y, et al. Clinicopathological features of hepatocellular carcinoma with fatty change: tumors with macrovesicular steatosis have better prognosis and aberrant expression patterns of perilipin and adipophilin. Pathol Int 2020;70:199-209.

81. Yamaguchi H, Condeelis J. Regulation of the actin cytoskeleton in cancer cell migration and invasion. Biochimica et biophysica acta 2007; 1773: 642-652.

82. Kim YY, Choi JY, Sirlin CB, An C, Kim MJ. Pitfalls and problems to be solved in the diagnostic CT/MRI Liver Imaging Reporting and Data System (LI-RADS). Eur Radiol 2019;29:1124-32.

83. Qin S. Guidelines on the diagnosis and treatment of primary liver cancer (2011 edition). Chin Clin Oncol 2012;1:10.

84. Hennedige T, Venkatesh SK. Advances in computed tomography and magnetic resonance imaging of hepatocellular carcinoma. World $\mathbf{J}$ Gastroenterol 2016;22:205-20.

85. Cheng S, Chen M, Cai J. Chinese expert consensus on multidisciplinary diagnosis and treatment of hepatocellular carcinoma with portal vein tumor thrombus: 2016 edition. Oncotarget 2017;8:8867-76.

86. Ponziani FR, Zocco MA, Campanale C, Rinninella E, Tortora A, et al. Portal vein thrombosis: insight into physiopathology, diagnosis, and treatment. World J Gastroenterol 2010;16:143-55.

87. Kanematsu M, Semelka RC, Leonardou P, Mastropasqua M, Lee JK. Hepatocellular carcinoma of diffuse type: MR imaging findings and clinical manifestations. J Magn Reson Imaging 2003;18:189-95.

88. An J, Lee KS, Kim KM. Clinical features and outcomes of patients with hepatocellular carcinoma complicated with bile duct invasion. Clin Mol Hepatol 2017;23:160-9.

89. Chotirosniramit A, Liwattanakun A, Lapisatepun W, Ko-Iam W, Sandhu T, et al. A single institution report of 19 hepatocellular carcinoma patients with bile duct tumor thrombus. J Hepatocell Carcinoma 2017;4:41-7.

90. Suh YG, Kim DY, Han KH, Seong J. Effective biliary drainage and proper treatment improve outcomes of hepatocellular carcinoma with obstructive jaundice. Gut Liver 2014;8:526-35.

91. Liu QY, Huang SQ, Chen JY, Li HG, Gao M, et al. Small hepatocellular carcinoma with bile duct tumor thrombi: CT and MRI findings. Abdom Imaging 2010;35:537-42.

92. Lu CH, Chen CL, Cheng YF, Huang TL, Tsang LL, et al. Correlation between imaging and pathologic findings in explanted livers of hepatocellular carcinoma cases. Transplant Proc 2010;42:830-3.

93. Liu Q, Chen J, Li H, Liang B, Zhang L, et al. Hepatocellular carcinoma with bile duct tumor thrombi: correlation of magnetic resonance imaging features to histopathologic manifestations. Eur J Radiol 2010;76:103-9.

94. Giannelli G, Rani B, Dituri F, Cao Y, Palasciano G. Moving towards personalised therapy in patients with hepatocellular carcinoma: the role of the microenvironment. Gut 2014;63:1668-76.

95. Ariizumi S, Kitagawa K, Kotera Y, Takahashi Y, Katagiri S, et al. A non-smooth tumor margin in the hepatobiliary phase of gadoxetic acid disodium (Gd-EOB-DTPA)-enhanced magnetic resonance imaging predicts microscopic portal vein invasion, intrahepatic metastasis, and early recurrence after hepatectomy in patients with hepatocellular carcinoma. J Hepatobiliary Pancreat Sci 2011;18:575-85.

96. Seo HJ, Kim GM, Kim JH, Kang WJ, Choi HJ. ${ }^{18}$ F-FDG PET/CT in hepatocellular carcinoma: detection of bone metastasis and prediction of prognosis. Nucl Med Commun 2015;36:226-33.

97. Hwang SH, Lee JW, Cho HJ, Kim KS, Choi GH, et al. Prognostic value of metabolic tumor volume and total lesion glycolysis on preoperative ${ }^{18} \mathrm{~F}-\mathrm{FDG}$ PET/CT in patients with very early and early hepatocellular carcinoma. Clin Nucl Med 2017;42:34-9.

98. Ho CL, Chen S, Yeung DW, Cheng TK. Dual-tracer PET/CT imaging in evaluation of metastatic hepatocellular carcinoma. J Nucl Med 2007;48:902-9.

99. Kitao A, Matsui O, Yoneda N, Kozaka K, Kobayashi S, et al. Hepatocellular carcinoma with $\beta$-catenin mutation: Imaging and pathologic characteristics. Radiology 2015;275:708-17.

100. Zucman-Rossi J, Jeannot E, Nhieu JT, Scoazec JY, Guettier C, et al. Genotype-phenotype correlation in hepatocellular adenoma: new 
classification and relationship with HCC. Hepatology 2006;43:515-24.

101. Kitao A, Matsui O, Yoneda N, Kozaka K, Kobayashi S, et al. Gadoxetic acid-enhanced MR imaging for hepatocellular carcinoma: molecular and genetic background. Eur Radiol 2020; Epub ahead of print. doi: 10.1007/s00330-020-06687-y.

102. Guzman G, Alagiozian-Angelova V, Layden-Almer JE, Layden TJ, Testa G, et al. p53, Ki-67, and serum alpha feto-protein as predictors of hepatocellular carcinoma recurrence in liver transplant patients. Mod Pathol 2005;18:1498-503.

103. Chen J, Chen C, Xia C, Huang Z, Zuo P, et al. Quantitative free-breathing dynamic contrast-enhanced MRI in hepatocellular carcinoma using gadoxetic acid: correlations with Ki67 proliferation status, histological grades, and microvascular density. Abdom Radiol (NY) 2018;43:1393-403.

104. Chen Y, Qin X, Long L, Zhang L, Huang Z, et al. Diagnostic value of Gd-EOB-DTPA-enhanced MRI for the expression of Ki67 and microvascular density in hepatocellular carcinoma. J Magn Reson Imaging 2019; Epub ahead of print. doi: 10.1002/jmri.26974.

105. Li Y, Chen J, Weng S, Sun H, Yan C, et al. Small hepatocellular carcinoma: using MRI to predict histological grade and Ki-67 expression. Clin Radiol 2019;74:653.e1-653.e9.

106. Surov A, Meyer HJ, Wienke A. Associations between apparent diffusion coefficient (ADC) and KI 67 in different tumors: a meta-analysis. Part 1: ADCmean. Oncotarget 2017;8:75434-44.

107. Ye Z, Jiang H, Chen J, Liu X, Wei Y, et al. Texture analysis on gadoxetic acid enhanced-MRI for predicting Ki-67 status in hepatocellular carcinoma: a prospective study. Chin J Cancer Res 2019;31:806-17.

108. Tsuchiya K, Komuta M, Yasui Y, Tamaki N, Hosokawa T, et al. Expression of keratin 19 is related to high recurrence of hepatocellular carcinoma after radiofrequency ablation. Oncology 2011;80:278-88.

109. Wang W, Gu D, Wei J, Ding Y, Yang L, et al. A radiomics-based biomarker for cytokeratin 19 status of hepatocellular carcinoma with gadoxetic acid-enhanced MRI. 2020;30:3004-14.

110. Chen J, Wu Z, Xia C, Jiang H, Liu X, et al. Noninvasive prediction of HCC with progenitor phenotype based on gadoxetic acid-enhanced MRI. Eur Radiol 2020;30:1232-42.

111. Hu XX, Wang WT, Yang L, Yang ZX, Liang HY, et al. MR features based on LI-RADS identify cytokeratin 19 status of hepatocellular carcinomas. Eur J Radiol 2019;113:7-14.

112. Choi SY, Kim SH, Park CK, Min JH, Lee JE, et al. Imaging features of gadoxetic acid-enhanced and diffusion-weighted MR imaging for identifying cytokeratin 19-positive hepatocellular carcinoma: a retrospective observational study. Radiology 2018;286:897-908.

113. Munz M, Baeuerle PA, Gires O. The emerging role of EpCAM in cancer and stem cell signaling. Cancer Res 2009;69:5627-9.

114. Zhou L, Zhu Y. The EpCAM overexpression is associated with clinicopathological significance and prognosis in hepatocellular carcinoma patients: a systematic review and meta-analysis. Int J Surg 2018;56:274-80.

115. Ji J, Yamashita T, Budhu A, Forgues M, Jia HL, et al. Identification of microRNA-181 by genome-wide screening as a critical player in EpCAM-positive hepatic cancer stem cells. Hepatology 2009;50:472-80. 